\title{
EREBEA
}

Revista de Humanidades

y Ciencias Sociales

NúM. 3 (2013), pp. 387-406

ISSN: 0214-0691

\section{LAS RAÍCES COLONIALES DE LA RELIGIOSIDAD BRASILEÑA}

\author{
Renata Siuda-Ambroziak \\ Universidad de Varsovia
}

Resumen

Las religiones y las religiosidades son unos de los fenómenos más importantes en la formación de las culturas y sociedades, siempre existiendo en la vinculación fuerte con el contexto donde han surgido $\mathrm{y}$ integrados con todos sus elementos. El objetivo de este artículo lo constituye un acercamiento a los procesos históricos de formación de la religiosidad brasileña desde la época colonial, haciendo especial hincapié en los factores que en mayor medida han contribuido a darle su carácter de apertura en la adaptación no sólo de la religión dominante (catolicismo lusitano), pero también de otras religiones, a las condiciones latinoamericanas, procesándolas in situ según las necesidades de los brasileños y convertiéndolas en una parte auténtica del 'alma brasileña'.

Palabras Clave

Brasil, religión, religiosidad, cultura brasileña, sincretismos

Fecha de recepción: 7 de junio de 2013

Fecha de aceptación: 4 de septiembre de 2013
Abstract

Both religions and religiosities have always been one of the most important phenomena in the process of formation of cultures and societies, existing in strong connection with the context in which they appeared and integrated with all of its ingredients. The objective of this article is to approach the historical processes of formation of the Brazilian religiosity since the colonial period, highlighting factors which to the greatest extent have contributed towards its qualities of openness in the adaptation of not only dominating religion (Lusitan Catholicism), but also other religions, to Latin American conditions, processing them in situ according to the necessities of Brazilian people and converting them into a genuine part of the 'Brazilian soul'.

KEYWORDS

Brazil, religion, religiosity, Brazilian culture, syncretisms 

La religión es uno de los principales fenómenos culturales, que proporciona tanto al individuo como a la sociedad entera modelos de conducta, valores y normas morales; dado que se trata de "un atrevido intento de captar todo el universum como un ser en el sentido humano", desempeña un "papel estratégico en la empresa del hombre para construir el mundo". ${ }^{1} \mathrm{Al}$ mismo tiempo, pensar en la religión como en un fenómeno que pudiera existir independientemente de colectivos y sociedades concretas "carece de sentido", ya que la religión "no se hace a sí misma. No posee sus propios medios de actuación" ", pues se expresa tanto en los sentimientos, las emociones, las imágenes y los símbolos, como en las prácticas cotidianas, la organización, las instituciones y las interacciones, vinculándose siempre al contexto donde ha surgido e integrándose fuertemente con todos los elementos del mismo.

Desde los inicios de su colonización y del establecimiento de sus fundamentos sociales y culturales, en la historia del Brasil la religión desempeñó un papel de protagonismo excepcional - la tierra brasileńa fue terreno de lucha misionera de la Iglesia por su 'dominio de las almas' y, a la par, núcleo, no oficialmente reconocido, de coexistencia de muchas otras religiones e influencias culturales, que se superpondrian y cruzarian creando un sistema cualitativo nuevo y sorprendente - la original religiosidad brasileńa, cuyos elementos siguen conservando su vigencia e importancia hasta nuestros dias. En gran medida, ha sido gracias a esta inusitada apertura y variedad en la esfera de la religiosidad del Brasil colonial que, a pesar de la dominación formal del catolicismo lusitano, las religiones e iglesias se han visto sometidas en el transcurso de los siglos a toda clase de influencias de factores internos y externos, que se han ido procesando in situ y que revelan los rasgos de carácter nacional y las necesidades de los brasileños, es decir, que han acabado por convertirse en una parte auténtica del 'alma brasileña'. Gracias a esta variedad de influencias, el 'ser brasileño' se sigue manifestando sin duda a través de un núcleo principal, vinculado a la civilización cristiana y occidental (católicolusitana), pero ya en un alto grado modificado por el fenómeno del encuentro (o choque) y el continuo proceso de mestizaje de culturas, con un resultado final de fuerte sincretismo. El objetivo de este artículo lo constituye un acercamiento a esos procesos de formación de la religiosidad especificamente brasileńa ya desde la época colonial, haciendo especial hincapié en los factores que en mayor medida

1 P.L. Berger, Święty baldachim, Kraków: Nomos, 2005, p. 60.

2 J. Beckford, Teoria spoteczna a religia, Kraków: Nomos, 2006, p. 25. 
han contribuido a darle su carácter de apertura e inculturización en la adaptación no sólo del catolicismo lusitano tradicional, pero también de otras religiones a las condiciones latinoamericanas.

Desde el momento en que el capellán de la expedición portuguesa ofició la primera misa para los descubridores de la tierra brasileńa, el cristianismo, más concretamente el catolicismo, pasó a ser un elemento de permanente presencia en la historia de la nueva colonia, cuyo primer nombre además fue el de 'Tierra de la Santa Cruz', aunque no tardando en rendirse frente al nombre de otro árbol: $e l$ pau-brasil (los portugueses elaboraban con el un precioso tinte rojo que se convirtiría en la primera riqueza de la colonia). ${ }^{3}$ Por su parte, el cronista Magalhães de Gandavo, comentó este cambio de forma sarcástica, aduciendo que "los pueblos cristianos deberian valorar más el árbol en que se hizo el milagro de la redención que un árbol que sirve solo para teñir los lienzos". ${ }^{4}$ Sin embargo, en la historia colonial de Brasil, ambos elementos, la necesidad de la propagación de la fe y el logro de un rápido avance social y material, que asegurara, sin necesidad alguna de creación de un etos del trabajo, a los colonizadores un estatus de 'clase ociosa's en términos de Veblen, y a la Corona pingües beneficios, siempre habrían de coexistir a menudo complementándose, conforme a las condicionantes vigentes históricas, que en buena medida explican estas aparentes contradicciones.

Para los portugueses, la colonización significaba al mismo tiempo, de acuerdo con el derecho al patronato ${ }^{6}$, la expansión territorial y mercantil y la propagación

3 E. Bueno (A viagem do descobrimento: a verdadeira história da expedição do Cabral, Rio de Janeiro: Objetiva, 1998, pp. 108-109), al escribir acerca de la llegada de los portugueses a la costa del Brasil, recuerda la participación de 17 sacerdotes en la expedición de Cabral (8 monjes franciscanos y 9 curas). Sin embargo, ninguno de ellos se quedó en el territorio recien descubierto. Decidieron quedarse, en cambio, 4 condenados, lo que no tardaría en ponerse en práctica para poblar el nuevo territorio.

4 Kula, M. Historia Brazylii. Wrocław: Ossolineum, 1988, p. 12.

5 'La clase ociosa' es una clase social que, gozando de grandes reservas financieras y de un consumo ostentoso, se aprovecha del trabajo de otros (también de esclavos). Es característica de sociedades donde existe una gran estratificación social y económica de carácter hereditario. A menudo, se da un fenómeno adicional: la difusión de una ideología basada en mejores y peores genes, color de piel, orden histórico (Veblen, Th. Teoria klasy próżniaczej. Waszawa: Wyd. MUZA S.A., 2008). En Brasil, esta clase ociosa apareció junto a los colonizadores portugueses y a las primeras grandes entregas de tierras, cuyos propietarios cultivaban un desprecio por el trabajo físico y fijaron un sistema económico basado en la esclavitud.

6 El derecho al patronato (ius patronatus) consistía en el reconocimiento por parte del Vaticano del poder político, económico y espiritual de los reyes iberos en los territorios recien descubiertos, sob pena de excomunión para quien se atreviera a negarlos. A cambio, los reyes se comprometían a difundir la doctrina cristiana en las colonias, a establecer estructuras para el clero, a participar en la gestión de los bienes eclesiásticos y a recoger los diezmos. Ello significaba, en la práctica, la absoluta dependencia de la Iglesia con respecto a la Corona en tierras de América y una falta de supervisión por parte del Vaticano. Otro instrumento importante de control de la monarquía sobre la Iglesia fue la Inquisición ibérica, dependiente de los reyes (Dussel, H.D. História da Igreja Latino-Americana. 
de la fe católica, aunque sin duda con un hincapié racional en el primero de estos elementos: "el eje alrededor del cual giró el proceso de cristianización fue la actividad comercial'7 y la religión fue en gran medida sólo un instrumento que legitimaba el proyecto colonial. De forma aún más clara, se puede juzgar la relación de la Corona portuguesa con la obligación evangélica, pues recordando la carta enviada por el rey Juan III al primer gobernador general, en la que afirmaba que la causa principal de la colonización del Brasil era la difusión de la fe, algunos escriben sin ambages: "Era una falsedad notoria. Pues como explicar de otro modo el hecho de que Brasil siguiera siendo 'tierra de misión' incluso tras haber conseguido la independencia."

Así pues, a pesar de que el catolicismo portugués fue, mediante el derecho al patronato y los privilegios concedidos a la Corona portuguesa por el Vaticano, un ejemplo preclaro de 'cesarpapismo', en el cual el monarca como plenipotenciario del Papa, por lo menos teóricamente, ejercía un control absoluto sobre la Iglesia católica y sus posesiones, la colonización portuguesa mantuvo durante largo tiempo y ante todo un carácter de imperio comercial, más dispuesto a obtener rápidos y altos beneficios de la colonia, que a sufragar los costes de la propagación de la fe. Buenos testimonios de ello serían la aversión de la Corona a fundar nuevos episcopados o parroquias, que dependieran financieramente de ella, los evidentes problemas para mantener al clero y, por ende, la busca por parte de el de hacendados ricos y poderosos protectores que les mantuvieran y convertirían en "capellanes de la familia de un catolicismo doméstico" . ' El sistema de patronato real reforzó así no solamente la tradición colonial de prestarse 'servicios recíprocos' entre los poderes eclesial y real, más también la de dependencia de la Iglesia, provocando que la posición privilegiada y monopolística del catolicismo se convirtiera de hecho en 'una jaula de oro' - la vida religiosa en la colonia se vió dominada por los grandes linajes de la aristocracia rural y sus latifundios autosuficientes y aislados ${ }^{10}$, que 'esponsorizaban' a los representantes coloniales de la Iglesia.

São Paulo: Edições Paulinas, 1989) .

7 Azzi, R. A cristandade colonial: um projeto autoritário. São Paulo: Paulus, 1987, p.33.

8 Bennassar, B. y Marin, R. (História do Brasil. Lisboa: Teorema, 2000, pp. 118-19) subrayan el hecho de que la primera diócesis se fundó medio siglo después del descubrimiento del Brasil, en Salvador de Bahía (1551), para la siguiente (en Río de Janeiro) hubo que esperar más de 100 años. Ello puede explicarse, en cierta medida, por la aversión del clero portugués a aceptar cargos en tierras de ultramar, algo del todo evidente: en los primeros siglos de la colonización, los obispos rechazaban a menudo nombramientos en la colonias, o los aceptaban, pero no aparecían después.

9 Matos, H.C.J. Nossa história. 500 anos de presença da Igreja Católica no Brasil. São Paulo: Paulinas, 2005 (v.I), pp.104-105.

10 A fin de facilitar la colonización sin que el rey debiera elevar los gastos, se dividieron las colonias en 15 capitanías con carácter hereditario; eran estas cinturones latitudinalmente paralelos desde la costa, cada una de unos $250 \mathrm{~km}$, entregados, según criterios feudales, a personajes importantes de la corte portuguesa con rango vitalicio. Los capitanes, separados entre sí por enormes distancias, sin medios de comunicación, permanecian aislados, manteniendo más contacto con Lisboa que con sus propios vecinos. 
Por eso, el poder se hallaba fuertemente descentralizado - muchos latifundistas (cuyo único deber consistía en poblar y administrar la tierra que desde el principio de la colonización se convirtió en un bien, no sólo reflejado en las reales fortunas amasadas gracias al comercio del azúcar, sino también, y quizás sobre todo, en un factor de prestigio social) lo detentaban de forma ilimitada sobre sus propiedades y establecían las normas, creando una esfera de influencias familiares entre clanes, por cuya protección todas las capas sociales más bajas tenían que esforzarse. ${ }^{11}$ El rey de Portugal, al menos en las cuestiones que concernían a la evangelización, más bien reigned but not ruled, dejándola gustosamente en manos de los representantes de las órdenes misioneras, no muy numerosas por otra parte (ante todo jesuitas, llamados los 'misioneros de la Corona'), cuyos fines eran no sólo la evangelización de los indígenas, sino también la de los propios colonizadores ${ }^{12}$, incluyendo la de los laicos de las muchas, fuertes y bien organizadas irmandades ${ }^{13}$

11Sobre el poder de los fazendeiros escribió Freyre, G. (Panowie i niewolnicy. Warszawa: PIW, 1985, p. 15): "la corte triunfó en Brasil sobre la Iglesia, sobre sus tentativas claras de dominar el pais. Sometidos los jesuitas, el señor en las plantaciones quedó como único señor de la colonia, el auténtico poder en el Brasil, más fuerte que los vicerreyes y los obispos".

12 Matos, H.C.J. Nossa história. 500 anos de presença da Igreja Católica no Brasil. São Paulo: Paulinas, 2005 (v.I), pp.88-89. Los primeros misioneros jesuitas, con el padre Manuel de Nóbrega a la cabeza, llegaron a la colonia portuguesa en 1549 (tras la conclusión del Vaticano, en virtud de la bula del papa Pablo III Sumblimis Deus de 1537, de que los indígenas tenían alma, eran seres humanos y, por tanto, se les podía evangelizar), junto al primer gobernador general, Tomé de Sousa. En 1549, llegó José de Anchieta (el primer santo 'vaticano' del panteón brasileño, honrado por el pueblo desde hace siglos y que fue canonizado en 1980 por el papa Juan Pablo II), llamado el Apóstol del Brasil. En el año 1551, se fundó el primer obispado con sede en Salvador de Bahía, pero a decir verdad, el peso de la evangelización lo llevaron, en Brasil, las órdenes religiosas, sobre todo jesuitas y franciscanos (Kula, M. Historia Brazylii. Wrocław: Ossolineum, 1988, p. 16-17), quienes, aparte de una labor spiritual y misionera, abrieron las primeras escuelas, orfelinatos y hospitales. La Corona, en vista de la falta crónica de mujeres blancas, no estuvo muy interesada por largo tiempo en abrir conventos para religiosas - el primero fue creado en el año 1677. Por este motivo, las mujeres blancas estuvieron condenadas durante el periodo colonial a las llamadas '7 c': casamiento, casa, cocina, cama, crianza, capilla, confesionario.

13 Irmandades (confrarias), hermandades, sociedades de personas laicas, que tenían como fin la difusión del catolicismo a través de la promoción del culto a un santo concreto, mediante procesiones pintorescas, celebraciones alegres de fiestas religiosas en su honor, desarrollo del culto a la 'intercesión', construcción de capillas, etc. e, aun cuando su fundación exigía el beneplácito oficial de la Iglesia y la Corona, se multiplicaron sin cesar. Prácticamente, la mayoría de los miembros de la sociedad colonial pertenecía a alguna de ellas - las hermandades, aparte de fines exclusivamente religiosos, eran también un elemento importante de cohesión social, de regulación de comportamiento y relaciones entre los diferentes grupos dispersos durante el periodo colonial a tenor del color de la piel, el estatus social, la detención del poder o la propiedad y la diversidad cultural, además promocionando la solidaridad entre sus miembros, asegurándoles el auxilio imprescindible, es decir, de alguna forma, aliviando los efectos de la esclavitud (Scarano, J. Devoção e escravidão: a Irmandade da Nossa Senhora do Rosário dos Pretos no distrito diamantino no século XVIII. São Paulo: Nacional, 1976, p. 147). La actitud positiva de las autoridades frente a su creación podría explicarse en gran medida por el hecho de que constituían un sustituto real del clero colonial, poco numeroso, con 
y ordens terceiras ${ }^{14}$, que a veces amenazaban a las débiles estructuras eclesiásticas, ejerciendo una mayor influencia en la sociedad que los sacerdotes o misioneros. ${ }^{15}$

Fueron precisamente estas irmandades las que difundieron la religiosidad popular portuguesa de corte medieval (fruto pintoresco de la convivencia secular de al menos tres grandes religiones en la Península Ibérica: cristianismo, judaismo e Islam) y respondían de la creación de rituales, celebraciones y plegarias con diferentes intenciones, por lo general ya sincréticos, lejos de la pureza teológica y de la ortodoxia y con fuertes elementos mágicos. Las hermandades promovían cultos de santos intermediarios e intercesores para cualquier necesidad y ocasión, formando además entre ellos y los mortales ordinarios lazos casi familiares (llamados santa parentela ${ }^{16}$ y predestinando de este modo particular a la colonia portuguesa a un permanente desarrollo del sincretismo religioso y de doctrinas 'heréticas' locales combatidas, aunque sin especial celo, por la Santa Inquisición portuguesa - en comparación con la espańola muy liberal y comprensiva. Su buena reputación se manifestaba en el trato relativamente benévolo dado a los heréticos - los inquisidores portugueses aparecían en la colonia únicamente en visitas oficiales (en el curso de tres siglos de colonización, hubo tan solo tres visitas de este tipo), por lo que a menudo no iniciaban pesquisas ni siquiera contra personas contra las cuales pesaban graves sospechas o pruebas de herejía, ante todo a causa de su 'misera' posición económica, es decir, de la falta de posibilidades de confiscarles los bienes. ${ }^{17}$ Las denuncias escritas a Lisboa eran tratadas por el Santo Oficio de

lo cual la Corona, por añadidura, se ahorraba su mantenimiento y seguía gozando del derecho de tomar sus diezmos con fines evangelizadores.

14 Ordens terceiras, órdenes laicas fundadas por órdenes religiosas, a las que solo podían pertenecer blancos de la elite católico-romana, cristianos viejos, es decir, los llamados homens bons (hombres buenos). Poseían sus propias iglesias, hospitales, bienes inmuebles y capital, por lo que tuvieron mucha influencia en la vida política y económica de la época, entrometiéndose también más de una vez en asuntos religiosos (Bennassar, B. y Marin, R. História do Brasil. Lisboa: Teorema, 2000,pp. 161-164).

15 Wagley, Ch. An Introduction to Brazil. New York, London: Columbia University Press, 1963, pp. 238-39.

16 La parentela es un sistema social, formado en la época colonial por los grandes latifundistas, consistente en la creación de lazos estrechos entre parientes, pero también con personas ajenas de la familia (agregados): conocidos, sirvientes, niños adoptados, hijos ilegítimos y apadrinados. Como observa Wagley (An Introduction to Brazil. New York, London: Columbia University Press, 1963, p. 199), el sistema de parentela es incluso actualmente uno de los más poderosos factores de unificación y cohesión nacional, hasta tal punto que las elites brasileñas se limitan a emular las estructuras fraguadas durante el periodo colonial.

17 Como lo subraya Gorenstein, L. „A terceira visitação do Santo Ofício às partes do Brasil” en: A inquisição em cheque: temas, controversias, estudos de caso. Vainfas R., B. Feitler, L. Lage (ed.). Rio de Janeiro: UERJ, 2006, pp. 25-31). Vainfas, R. (Trópicos dos pecados: moral, sexualidade e Inquisiçâo no Brasil. Rio de Janeiro: Nova Fronteira, 1997, p. 303) estima que sólo alrededor de un 7\% de las denuncias acabó por ser investigada, de las que una media de un $8,3 \%$ registró la sentencia a la pena capital. 
la metrópolis de forma excepcionalmente 'liviana' y, por lo general, no se sacaban de ellas ningunas consecuencias procesales. ${ }^{18}$ Así, los rasgos característicos del catolicismo brasileño, esto es, "la presencia institucional débil de la Iglesia en la sociedad brasileña y la propagación dinámica de diversas formas quasi-católicas de religiosidad popular fuera del control del clero tendrian su origen en la realidad colonial del Brasil'. ${ }^{19}$

Sin lugar a dudas, también ejerció una gran influencia en la vida religiosa del Brasil el hecho de que, al contrario que en la América española, allí no se desarrollara por mucho tiempo ni un aparato complejo de poder, ni una civilización urbana, ni siquiera producción para el mercado interior - la colonización portuguesa al principio se desarrolló únicamente a lo largo de la costa, en vista de los elevados costes del transporte interno, $y$, como ya señalamos, se vio fuertemente condicionada no tanto por el deseo de difundir la fe, como por el afán de lucro. Marcada por grandes expectativas económicas, la colonización portuguesa del Nuevo Mundo se llevó a cabo de una forma asistemática e inarmónica, dependiendo en gran medida de la geografía física del inmenso territorio del Brasil, dividido en regiones, de las cuales todas y cada se diferenciaban por el clima, la forma del terreno, el modelo histórico de asentamiento y desarrollo económico basado en productos o materias primas concretos. Las regiones se desarrollaron en condiciones de aislamiento unas de otras y recibían contingentes de población inmigrante de muy diverso origen, lo que produjo a su vez grandes diferencias culturales. ${ }^{20}$ Esta fuerte diversificación regional gravitó también sobre el carácter policéntrico del Brasil en lo referente a su 'geografía religiosa', debilitando en un periodo posterior los centros católicos más importantes de devoción mariana (por ejemplo, el célebre santuario de Aparecida do Norte). ${ }^{21}$ En cada región, el catolicismo brasileño se concentraba en diferentes símbolos, se caracterizaba por diferentes influencias culturales y sincretismos y poseía sus santuarios propios, cuya significación y ascendiente eran incuestionables para los habitantes. Este

18 Esta opinión es también compartida por Feitler, B. „Poder episcopal e ação inquisitorial no Brasil" en: A inquisição em cheque: temas, controversias, estudos de caso. Vainfas R., B. Feitler, L. Lage (ed.). Rio de Janeiro: UERJ, 2006, pp. 33-45.

19 Como lo explica Casanova, J. (Religie publiczne w nowoczesnym świecie. Kraków: Nomos, 2005, p.197).

20 Wagley, Ch. An Introduction to Brazil. New York, London: Columbia University Press, 1963 , p. 28.

21 Como advierte Jackowski, A. (Święta przestrzeń świata. Podstawy geografii religii. Kraków: Wyd. UJ, 2003, p. 131, 164), América Latina es el segundo continente, después de Europa, con el mayor número de lugares 'santos', metas de peregrinaje. Hay 973, de las cuales la mayoría son el resultado del sincretismo entre las religiones precolombinas y el catolicismo; en Brasil, se encuentra uno de los mayores santuarios marianos del continente, Nossa Senhora de Aparecida, que ocupa el quinto lugar en el mundo por lo que respecta al número de peregrinos que la visitan, ex aequo con Jasna Gora en Polonia, Fátima en Portugal o Santiago de Compostela en España. 
regionalismo religioso se situaba a menudo al pie del mismo precipicio, entre las doctrinas oficiales de las instituciones religiosas y sus ejecutores regionales, por un lado, y las prácticas cotidianas de los adeptos, por otro. Incluso el título y el culto de la 'Reina del Brasil' con el que desde 1904 se denomina formalmente a la Virgen de la Aparecida (en 1930 reconocida por el Papa Pío XI como Santa Patrona del Brasil), cuya devoción fue impuesta desde arriba por la jerarquía eclesiástica, no 'encuentra su lugar' en el inconsciente de todos los fieles, unidos sobre todo a sus santos locales (también a María, bajo diversas denominaciones, a quien se suele acudir como intercesora con la mayor frecuencia). En suma, en Brasil, "el pueblo y el clero no rezan necesariamente del mismo modo, ni frente a las mismas imágenes". ${ }^{22}$

De forma inevitable, la religiosidad brasileña desde el principio de la colonización fue influenciada también por la fascinación recíproca de los mundos encontrados, tan diferentes entre sí, de las dos civilizaciones, la europea y la indígena, y los planes de cooperación pacífica y evangelización que, desgraciadamente, terminaron rapidamente con la rivalidad por el poder, la riqueza, las mujeres y la tierra: "incluso si los primeros contactos entre los europeos y los representantes de culturas no europeas fueron amistosos, no tardaron, sin embargo, en colisionar, provocando que la parte más débil se viera condenada a la aniquilación o a la pérdida de la soberanía y la identidad cultural'. ${ }^{23}$ La admiración por la ingenuidad, la belleza física o la posibilidad de convertir de veras a las tribus brasileńas, tras lo cual se hallaba el cálculo de conseguir mano de obra esclava, pronto cedió el paso a la convicción de la inferioridad natural de los indígenas con respeto a los portugueses. Ya, por aquel entonces, empezaron (los indígenas) no a ser tenidos por 'ángeles inocentes', sino más bien por bárbaros contumaces (a quienes había que civilizar a la fuerza mediante la sumisión total al yugo portugués y su conversión al cristianismo y al 'lusitanismo'), que se guiaban por sus instintos y pasiones (canibalismo y poligamia), descritos por los propios misioneros como "bestias salvajes" que no poseen "nife, ni derecho, ni rey"24. El jesuita Manuel de Nobrega sugirió, con la idea de la necesidad de crear reducciones, que solo la incapacitación de los indígenas puede aportar beneficios espirituales y materiales al império y a ellos mismos, dado que,

22 Según advierte Fernandes, R.C. Romarias da Paixão. Rio de Janeiro: Rocco, 1994, p.42, 106,108 .

23 Grzymała-Moszczyńska, H. „Klatka czy most? Rola religii w adaptacji kulturowej imigrantów” en: Migracje. Religie i kościoty wobec migracji i migrantów. Migracje i społeczeństwo nr 14, J.E. Zamojski (ed.). Warszawa: IH PAN, 2009, pp. 10-18, p.12.

24 Matos, H.C.J. Nossa história. 500 anos de presença da Igreja Católica no Brasil. São Paulo: Paulinas, 2005 (v.I), p. 152, 62. Con todo, Antonio Vieira cambió su postura frente a la esclavitud de los indígenas. A menudo saldría en su defensa y consiguió incluso de la Corona una ley, a corto plazo, favorable para sus protegidos. Sin embargo, los intentos de llevarla a la práctica acabaron con la rebelión de los colonos contra los jesuitas, y el propio Vieira, denunciado a la Inquisición, estuvo encarcelado durante 2 años. 
en una situación de esclavitud y de trabajo organizado y sistemático, empezarian a vivir, por miedo y disciplina como "seres racionales" 25 .

Así, el interés económico y la supuesta necesidad de convertir a los indígenas a la manera de los colonizadores prevalecieron sobre la autenticidad de la evangelización pacífica. Bajo el concepto de 'guerra justa' fue introducida la posibilidad de su esclavitud en caso de que practicaran el canibalismo, lucharan contra los colonizadores o se negaran a aceptar el cristianismo o las propuestas de colaboración 'comercial'. La dispersión de los indígenas favoreció decididamente esta postura, ya que, no se creó ningun tipo de organización que, aun en la derrota, pudiera constituir una base estable de la colonización portuguesa ${ }^{26}$. A su vez, los portugueses, al contrario de los españoles, no tuvieron que liquidar a sangre y fuego estructuras seculares de imperios de grandes dinastías, ni destruir templos, exterminar castas sacerdotales y quemar libros sagrados. No existió en Brasil ninguna presión inicial destinada a negar de modo rápido y eficaz los hasta entonces modelos culturales, por lo que tampoco hubo resistencia por parte de las tribus indígenas. Con todo, estas sufrieron un exterminio, tanto por causas accidentales (virus y bacterias), como deliberadas.

Los indígenas, aunque eran considerados oficialmente como seres humanos y los portugueses alegaban su evangelización como pretexto para llevar a cabo su política colonial, eran esclavizados - sin embargo, a la introducción del esclavismo, impuesto con fines económicos y a causa de la notable falta de mano de obra, siempre le acompañó la casuística religiosa de la necesidad de evangelizar; en muchos casos, como se aseguraba, era la única manera de que los paganos pudieran ser bautizados y salvados. En suma, ante la superioridad material y organizativa de los portugueses, la resistencia indígena apareció, en un principio por lo menos, como algo carente de sentido - la posibilidad de supervivencia se limitaba bien a una huida al interior del continente y al consiguiente aislamiento del hombre blanco, bien a la aceptación de la nueva religión junto a una total conformidad con su status de esclavo. Sin embargo, de acuerdo a la tradición de sus antepasados, los indígenas seguían celebrando sus rituales, adaptados ligeramente a las exigencias de la nueva confesión, y honrando a sus viejos dioses en el proceso de la progresiva ‘americanización’ de la liturgia eclesiástica, lo que fue formalmente

25 Ribeiro, D., Moreira Neto, C.A. A fundação do Brasil: testemunhos 1500-1700. Petrópolis: Vozes, 1993, p. 26.

26Los eruditos, como escribe Kula (1988: 9), han intentado buscar las causas tanto en las dificultades como, al contrario, en la extrema facilidad de la vida en el trópico, lanzando la hipótesis de la falta de necesidad o la falta de posibilidad de hacerse con los excedentes económicos imprescindibles para la creación de unas estructuras sociales más complejas. La acumulación de riquezas o reservas o la inversión para el futuro era algo incomprensible y absurdo en el seno de las culturas indígenas brasileñas, sobre todo si tenemos en cuenta un clima y un medio en el que conservar algo carece de sentido, dada la gran abundancia de alimentos. 
condenado por los primeros misioneros. Pero, al ser estos poco numerosos y al estar a menudo absortos en la tarea material y organizativa de edificación de la Iglesia en la colonia, así como en las disputas acerbas entre ordenes ${ }^{27}$, los sacerdotes permitieron estas prácticas suponiendo que, más tarde o más temprano, acabarían por extinguirse de las nuevas tierras. De esta forma, se dieron situaciones en las que la creencia en los dioses indígenas, en los sortilegios y en la magia convivía pacificamente con la fe en Cristo Salvador, cosa característica en los momentos de derrumbamiento de las estructuras tradicionales de una determinada cultura, cuando son aceptados elementos de otra, cercana, ya infiltrados, que facilitan los comportamientos, la elaboración de una nueva imagen del mundo y la posibilidad de enfrentarse a situaciones de crisis. Así, los principios de la nueva religión no vinieron a sustituir a los de la anterior, sino que más bien se superpusieron y coexistieron con la tradición, siendo interpretados por los indígenas de acorde a sus propios modelos culturales. ${ }^{28}$

Al principio, los sincretismos religiosos se vieron también favorecidos debido al gran problema que suponía la traduccion del Evangelio y los principios de la fe a las lenguas autóctonas (para este fin se creó la lingua geral, basada sobre todo en el tupiguarani y que fue adaptada por los misioneros a las necesidades tanto de los colonizadores como de las tribus indígenas que se servían de otras lenguas). La dificultad era del todo lógica, dada la falta de conceptos equivalentes en las lenguas y culturas de los pueblos evangelizados; además, la aparente similitud doctrinal en ciertos casos se refería a contenidos completamente diferentes a los del cristianismo: "por lo tanto, el problema no es si la Virgen tiene la cara negra o india o si va vestida con la falda tradicional de hierba, sino que el concepto de Cristo, hijo de Dios, amado por el Padre, contiene una serie de sentidos culturales internos, occidentales, intraducibles a otras lenguas, por falta de conceptos similares". ${ }^{29}$ Todo ello condujo rápidamente a un peculiar paralelismo religioso (o sincretismo dualista $)^{30}$

27 Bennassar, B., R. Marín (História do Brasil. Lisboa: Teorema, 2000, pp.132-134) subrayan en particular la escala de conflictos entre jesuitas y franciscanos, que no se limitaban a las rińas verbales, llegadas a un tal encarnizamiento, que obligó al rey a promulgar en 1693 una ley especial por la cual se dividían las tierras de misión para cada una de las órdenes, que llevarían su labor por separado. Problema aparte lo constituirán después las múltiples órdenes femeninas, que abusaban exageradamente de esclavas y sirvientas. Según los autores, el arzobispo de Bahía, en 1751, la orden de las claretianas en Salvador de Bahía contaba con 90 monjas, de las cuales 63 poseían cada una 2 esclavas y el resto 1 .

28 Szyjewski, A. Etnologia religii. Kraków: Wyd. Nomos, 2001, p. 550.

29 Szyjewski, A. Etnologia religii. Kraków: Wyd. Nomos, 2001, p. 544)

30 Posern-Zielinski (en: Szyjewski, A. Etnologia religii. Kraków: Wyd. Nomos, 2001, p. 550) recuerda una situación semejante al explicar el fenómeno, característico en Brasil, del 'sincretismo dualista', que "consiste en la coexistencia pacifica y armónica de dos esferas complementarias, pero separadas, de la realidad religiosa: una dominada por elementos cristianos y otra dominada por contenidos indigenas, que funcionan de modo que cada una de ellas se manifiesta a traves de rituales, lugares santos, simbolos, parafernalia, mitos, invocaciones y sacerdotes diferentes, aunque ambas se hallan unidas por el 
consistente en la pertenencia simultánea a la Iglesia y a los cultos tradicionales, familiares, sin necesidad de elegir entre una de ambas opciones, en apariencia contradictorias, lo que permitía a los brasileños la profesión de dos religiones, en la imaginación de sus seguidores perfectamente complementarias. Ha sido de este modo como algunos de las características indígenas de las creencias, mitos y rituales han permanecido hasta hoy en día en este progresivo mestizaje cultural y étnico de la religiosidad brasileña, si bien es seguro que, a causa del gran número de tribus y de su dispersión, se han caracterizado en el curso de los siglos por la variedad y la riqueza de las formas originales de expresión. Tal vez sea precisamente por esta sumisión, relativamente rápida y fácil, aunque a veces solo aparente ${ }^{31}$, de los indígenas brasileńos a la cultura portuguesa y a la dominación de la colonización masculina, lo que posibilitó, un poco sesgadamente, tanto la permanencia de ciertos usos y conocimientos, tales como el empleo de la hamaca, el consumo de mandioca o la receta del curaré, como de las religiones indígenas, que incluso ahora ejercen su influencia sobre el enfoque de la cuestión religiosa en el Brasil.

La brutal disminución del número de indígenas en las primeras décadas de la colonización y, por consiguiente, de su influencia cultural y religiosa, fue paliada sin dilación por los portugueses mediante el tráfico de esclavos negros, que aseguraron, hasta la abolición (1888), la mano de obra a las insaciables plantaciones del Nordeste, lo que permitió a los 'barones del azúcar' brasileños amasar sus legendarias fortunas y - destinar buena parte de ellas a erigir obras arquitectónicas de caracter religioso (entre las cuales destacan iglesias como la de Nosso Senhor de Bomfin en Salvador de Bahía) ${ }^{32}$. De este modo, y a la par que se importaban africanos, el Nordeste se iba convirtiendo en la región de mestizaje que daría como fruto los modelos, excepcionalmente plásticos y dinámicos, del 'ser brasileño', en lo tocante a cocina, atuendo, formas de ocio y, last but not least, en la religiosidad brasileña, sobre todo en su versión popular, que conservaría muchas prácticas

mismo sistema sacral de garantía de exito económico, defensa de la vida y la salud y promesas de equilibrio cósmico y social'.

31 Cabe recordar que también tuvieron lugar sangrientas venganzas y rebeliones organizadas por los indígenas. En 1712, estos asesinaron brutalmente a uno de los grandes latifundistas, tras lo cual la revuelta se extendió prácticamente por todo el Nordeste. Otra, más pacífica forma de resistencia, fueron los movimientos mesiánicos, en los cuales los indígenas se identificaban con el Salvador y auguraban el fin de la civilización del hombre blanco (Matos, H.C.J. Nossa história. 500 anos de presença da Igreja Católica no Brasil. São Paulo: Paulinas, 2005, v.I, p. 66)

32 Resulta curioso que esta iglesia lleva de verdad dos nombres, aparte del ya mencionado, es llamada también 'templo de Oxalá, el principal dios afrobrasileño del culto candomblé, que surgió en el Nordeste entre los esclavos africanos y sus descendientes. Actualmente, los adeptos al candomblé no son necesariamente afrobrasileños y sus deidades han sido sincretizadas con los santos católicos. Incluso en algunas iglesias celebraciones religiosas son organizadas en común por sacerdotes católicos y sacerdotes de cultos afrobrasileños (así es, por ejemplo, en San Salvador de Bahía) y la participación en ellas no significa tanto una salida del catolicismo, como más bien un complemento importante del mismo. 
sincréticas, elementos de magia y supersticiones. Los esclavos tuvieron una participación excepcional en la difusión de las creencias africanas y, por ende, en la creación de los sincretismos. ${ }^{33}$ Sobre todo, contribuyeron a ello las famosas ayas y nodrizas de color que criaban a los hijos de los señores y "para que se durmieran, les cantaban melodias africanas, les entretenian o les apaciguaban con cuentos, leyendas y narraciones miticas del continente negro". De este modo, la cultura africana fue penetrando sutilmente en la vida de los portugueses católicos. Gracias, por tanto, a la permanente presencia de los esclavos y el servicio, el catolicismo de la plantación se fue abriendo cada vez más a las influencias y se hizo paulatinamente más 'sincreticamente descuidado', 'familiar', 'doméstico', se cimentaba en la confianza familiar, e incluso en una peculiar fraternidad entre Dios y los Santos que, a semejanza de las deidades africanas, también habitaban en medio de los humanos bajo la forma de figuritas de un altar casero o de miembros de la ramificada parentela, que adolecían de vicios y debilidades (ser santo y ser moral aparecían como dos cosas diferentes - los santos sincréticos solían comportarse de modo algo indecente y hasta inmoral desde el punto de vista cristiano), que exigían sacrificios concretos a cambio de cumplir con los ruegos y peticiones, a los que se dirigían promesas y votos ${ }^{34}$ y a los que, en caso de no atender las súplicas de los devotos, se les podía castigar de diversas formas (entre otros métodos, bien se les retiraba del panteón doméstico para despúes, si por fin se cumplían las peticiones, restituirles a su lugar). Se ejercía así una fuerte presión sobre los 'intermediarios' entre Dios y los seres humanos, a fin de lograr resultados concretos: por ejemplo, en época de sequía, se colocaban las figuritas de los santos encima de los tejados a pleno sol; en tiempo de inundaciones, se las exponía a merced del viento y la lluvia, conforme a los principios de un contrato aceptado a priori, que debía ser respetado por ambas partes. Esta especie de compenetración del 'hombre cordial brasileño' ${ }^{35}$ con la esfera de lo sacrum permitía un culto religioso libre y relajado, exento de rigor y necesidad de dogmas, y favorecía la proliferación de capillitas y pequeños altares domésticos. Todo ello explicaría historias como la de la prostituta que, tras su conversión, llevaba una vida ascética, dedicada exclusivamente a la

33 Tal y como afirman Freyre, G. (Panowie i niewolnicy. Warszawa: PIW, 1985) y Pilaszewicz S. (Religie Afryki. Warszawa: UW, 2000, p.335).

34 Los votos, en el catolicismo popular, consisten a menudo en una promesa de peregrinación, durante la cual se lleva a cuestas la cruz hasta un lugar santo, para que, como explica Fernandes, R.C. (Romarias da Paixão. Rio de Janeiro: Rocco, 1994, p. 160) "en vez de llevarla solo, entregársela a Dios."

35 El concepto de ' hombre cordial', acunado por Sergio Buarque de Holanda, significa un hombre que se guia por el corazón, los sentimientos y las preferencias personales, y no por la razón, concediendo especial importancia a los lazos de sangre, a las conductas afectivas en las relaciones interpersonales, a la espontaneidad, a la falta de respeto por el formalismo y la disciplina (Malinowski, M. W poszukiwaniu brazylijskości. Gtówne nurty brazylijskiej myśli spotecznej w XX wieku. Warszawa: CESLA, 2011, p. 261). 
oración y, según decía, "era visitada a diario por el Niño Jesús, quien le peinaba sus largos cabellos y a quien ella, en agradecimiento, amamantaba con su negro seno". ${ }^{36}$

Pero, al mismo tiempo, los africanos en Brasil participaban obligatoriamente en todos los oficios católicos y prácticas religiosas de sus amos, ya que el catolicismo era impuesto desde arriba (y no aceptado mediante una conversión voluntaria). En respuesta a esa dominación formal del catolicismo, aparecería, por una parte, una resistencia interna entre los potenciales prosélitos africanos, para quienes la única posibilidad de mantener las raíces culturales era precisamente la de mantener la religiosidad de sus abuelos, y, por otra parte, ante la inevitable y forzada presión en condiciones de total dependencia, una fuerte tendencia a la religiosidad ecléctica y sincrética. Gracias a ello, los africanos consiguieron, siempre a caballo entre esos dos mundos religiosos, el oficial y el prohibido, conservar durante siglos sus creencias familiares étnicas, ocultando bajo figuritas de santos católicos todo el panteón de deidades africanas e intentando, tal y como al principio habían hecho los indígenas, granjearse su benevolencia con ayuda de rituales y sacrificios ancestrales. Así surgieron los cultos afrocristianos, que se desarrollaron entre los esclavos y que manifestaron una gran energía, ademas de una enorme fuerza de atracción. No obstante, estos cultos se vieron modificados por el catolicismo, por las culturas indígenas locales y también por las diferencias entre las mismas tribus africanas destinadas a las plantaciones azucareras - a fin de evitar rebeliones, se evitaba comprar esclavos del mismo clan o familia para una plantación; asimismo, tampoco se aprobaba que los esclavos se reprodujeran, ya que salía más barato comprar un esclavo adulto que criar a los niños nacidos de familias de esclavos. ${ }^{37}$ Por consiguiente, las religiones afrobrasileńas, como una singular emanación del eclecticismo brasileño de la época colonial, aparecieron donde, por lo menos teóricamente, todos los esclavos habían sido integrados en la Iglesia católica mediante bautismos forzados, pero las religiones africanas primigenias habían sido transmitidas, vía oral, de generación en generación, y respondían a las continuas necesidades sociales de una religión de carácter espiritista, extática y escapista, ofreciendo una 'válvula de escape' social. Aquí radica seguramente la causa de que la demanda de religiones sincréticas no disminuyera ni siquiera tras

36 Bennassar, B., R. Marín. História do Brasil. Lisboa: Teorema, 2000, p. 167, 448. No deja de ser curioso que, en la cultura religiosa de los brasileños, Jesús sea presentado sobre todo como un niño indefenso en brazos de su madre. A su vez, la Madre de Cristo es considerada, ante la distancia de un Dios Padre 'ausente', como la principal mediadora entre el hombre y la divinidad, por encima de toda la gran familia de santos igualmente 'serviciales' (Fernandes, R.C. Romarias da Paixão. Rio de Janeiro: Rocco, 1994,p. 118).

37 Wagley, Ch. An Introduction to Brazil. New York, London: Columbia University Press, 1963, p. 21. Bennassar, B., R. Marín. História do Brasil. Lisboa: Teorema, 2000, p. 254 presentan cifras aproximativas, según las cuales más de la mitad de los esclavos negros nacidos en las plantaciones no llegó a cumplir los 10 años. 
la abolición de la esclavitud, a resultas de la cual la mayoría de esclavos abandonó las plantaciones, pero siguió quedándose en el último escalafón de la pirámide social. Estas religiones posibilitaron a sus seguidores transgredir las fronteras de determinadas normas brasileñas en el terreno cultural y económico, generalmente de forma opuesta a la posición social de los creyentes e su bajo estatus social. ${ }^{38}$

Sin duda, esta clase de fenómenos religiosos sincréticos fueron posibles gracias a la herencia cultural africana que, desde el principio, aceptó la ampliación del panteón de sus deidades y el 'intercambio' de las mismas sin ningún tipo de conflicto. En Brasil, los mitos africanos, transmitidos oralmente, en su encuentro con la cultura autóctona y lusitana, sufrieron una evolución permanente, puesto que carecían de dogmas rígidos, de cualquier clase de teología elaborada y de figuras de padres-fundadores, además de ser variables según el grupo étnico. No hubo, pues, lugar para la doctrina o la ortodoxia - las religiones africanas siempre fueron más sentidas y experimentadas que verbalizadas, siendo uno de sus rasgos principales la unión, el enlace permanente con determinadas deidades según el grado de su eficacia, y fue bajo esta influencia que se formaría en el periodo colonial 'la apertura religiosa' de los brasileños, su capacidad para integrar nuevos elementos culturales y prácticas de otras religiones, además de su habilidad para pasar del culto de un dios a otro, del ritual de una confesión a otro, incluso de unirlos arriesgadamente, procurando no ofenderlos y permitiendo el acuerdo de diferentes aspectos de la religión africana con los dogmas de la cristiana: la identificación de Dios con Olorun, de Satán con Exú, de los ángeles y santos con los mediadores divinos - los orixás.

Como puede advertirse, tanto la influencia y la significación de las culturas indígenas, como de las africanas, son difíciles de estimar, aunque son indiscutibles por lo que respecta a la formación, durante el periodo colonial, del ambiente de profundo sincretismo y eclecticismo religioso que acabó por envolver al cristianismo brasileño, desde el principio coexistente con otras religiones y con la variedad de habitantes ya nacidos en la colonia. No obstante, era el ante todo el mismo catolicismo lusitano de las plantaciones el que decidiría del desarrollo de la religiosidad brasileña, mostrándose libre del excesivo formalismo y relativamente flexible, con capacidad para absorber elementos extraños y adaptarse a las necesidades de los adeptos. ${ }^{39}$ Este singular 'relajamiento' del catolicismo colonial brasileño pudo ser la

38 Según Pilaszewicz, S. Religie Afryki. Warszawa: UW, 2000, p. 118. Acerca de esta función compensatoria de la religión afrobrasileña, escribe Kolankiewicz, L. (Samba z bogami. Opowieśc antropologiczna. Warszawa: Wydawnictwo KR, 2007, p. 150) que los participantes en sus ceremonias religiosas sufren de miseria en la vida diaria y que la pompa de los trajes festivos de sus dioses es una suerte de premio para los danzantes negros, que además durante el ritual se encuentran en el centro de atención. De ellos fluye el esplendor tanto como la locura, convirtiéndose esto en una experiencia, que es valiosa por sí misma y a la que nada puede comparársela.

39 Poulat (en: Hervieu-Léger, D. Religia jako pamięć. Kraków: Wyd. Nomos, 2007, p. 183) considera : "En una sociedad donde la tierra es la base de la economia y fuente de nobleza, el cristianismo 
causa de que gran parte de los brasileños se declararan católicos, no tanto debido al celo y a la ortodoxia de su fe, sino a la tradición en la que habían sido educados. ${ }^{40}$ Es más, su filiación formal no se reflejaba a menudo en su estilo de vida, en sus valores confesos y en su moral; frecuentemente, en las iglesias, no solo se bailaba y se festejaba, sino que también se flirteaba. Los miembros del clero tenían familia propia, manifestando a la par una gran tolerancia para con las costumbres de la época, sometido como estaba a la influencia del eclecticismo y sincretismo surgido en las grandes haciendas de esclavos. Por otra parte, al gozar de su propia capilla y sacerdote propio, las fazendas solían ser autosuficientes en cuanto a los servicios espirituales y, a su vez, el sacerdote, mantenido por el patrón, impartía los sacramentos y absolvía, prácticamente, a petición. Así, el catolicismo brasileño multicultural, crecido en las plantaciones de azúcar, se adaptaba de forma ideal a las necesidades diarias y a la moral de los plantadores (muy lejos, seguro, del ideal cristiano), era ingénuo y espontáneamente infantil, ${ }^{41}$ más dependiente de familias concretas y de las cabezas de estas familias que de la Corona. Era una religiosidad a la manera muito Deus, pouco padre, muito ceu e pouca igreja, muita prece e pouca missa (mucho Dios, poco cura, mucho cielo y poca iglesia, mucho rezo y poca misa); una religiosidad en la que la crueldad de la esclavitud se amalgamaba con una devoción (aunque elástica y hetereodoxa) auténtica y con el sentimiento de que el mundo divino y humano se entrelazaban en la tierra. Nada cambió durante la época del imperio $(1822)^{42}$, lo que atestigua la opinión del primer nuncio apostólico en Brasil: "Aqui la religiosidad se manifiesta ante todo en la música, en el sonido de las campanas y fuegos artificiales, en las fiestas celebradas, con ocasiones diversas, en las iglesias y por una gran dosis de permisividady frivolidad. El peor es el clero, en quien se unen la ignoracia y un inmoral relajamiento de costumbres". ${ }^{43}$

cobró una forma campesina que ni el paso del tiempo, ni los profundos cambios habidos en los medios de producción, lograron borrar (...) Esta situación económico-geográfica, que pesó tanto en la organización eclesiástica, se implantó hondamente en la mentalidad católica, no sólo a nivel de la llamada religión popular, con sus tradiciones y sincretismos propios, sino también en formas más oficiales de la liturgia, la instrucción, la espiritualidad e incluso el derecho canónico".

40 Como estima Wagley, Ch. An Introduction to Brazil. New York, London: Columbia University Press, 1963, p.233.

41 Azevedo de, F. Brazilian Culture. An Introduction to the Study of Culture in Brazil. New York: Macmillan, 1950, p. 211.

$42 \mathrm{La}$ independencia se logró en Brasil con la separación pacífica de la metrópolis, Portugal, y mediante el mantenimiento de la unión dinástica. Cabe subrayar que los partidarios de la independencia fueron, entre otros, sacerdotes católicos liberales que participaron en todas las conspiraciones a menudo pagando un precio muy alto, con la libertad o con la vida (Carvalho, G.V. A liderança do clero nas revoluçóes republicanas: 1817-1824. Petropólis: Vozes, 1980, pp. 29-30). Cuando el 7 de septiembre de 1822, el principe regente decidió separar al Brasil de la monarqua portuguesa y se entronizó emperador, los obispos brasileños apoyaron unánimemente tanto la independencia, como la opción monárquica. En 1826, el Vaticano reconoció oficialmente la independencia del Brasil.

43 Accioly, H. Os primeiros núncios no Brasil. São Paulo: Instituto Progresso Editorial, 1949, 
No obstante, con toda su frivolidad espontánea, su creatividad religiosa, su diversidad, sus desigualdades y su inmensidad territorial, Brasil, desde el principio de la colonización, formó una unidad. Aun cuando los brasileños eran muy diferentes en su aspecto, origen, pertenencia a clase social, nivel de propiedad o estilo de vida, la sociedad brasileña se hizo sorprendentemente coherente y con un fuerte sentido de comunidad cultural en su 'ser brasileño': "Brasil es un pais que, a pesar de la inmensidad territorial (y por ello también grandes diferencias geográficas), a pesar de la estirpe multiétnica y multicultural, a pesar de la evidente estratificación social y, por último, a pesar de los largos periodos de 'impasse' politico, ha conseguido tres objetivos: en primer lugar, se ha creado y ha mantenido una posición hegemónica a nivel regional; en segundo lugar, ha conservado, pese a la división en estados autonómicos, la unidad estatal de todo el territorio; en tercer lugar, ha elaborado una esfera original de comunidad identificatoria, simbólica (...). E incluso, si como desea Gilberto Freyre, Brasil es el resultado de antagonismos, ello no significa en absoluto que hayan desaparecido en algún momento, mas al contrario, siguen en pie; algunos, con formas inalterables, otros prácticamente iguales a siglos atrás. Bajo el paraguas de la comunidad brasileña, hasta hoy en dia, continuan en sordina muchas contradicciones" ${ }^{44}$

Hasta cierto punto, esta unidad brasileña en la diversidad fue, sin duda, impuesta por la uniformidad de las estructuras administrativas coloniales, pero no se puede explicar esta cohesión interna únicamente por factores político-administrativos, pues la paradoja brasileña se manifiesta en su más alto grado en el campo cultural, y, por ende, también en la esfera religiosa, y procede de la época colonial. Como ya señalé, los monarcas portugueses reinaron en Brasil de un modo más liberal y tolerante que lo hicieron sus homólogos espańoles en su parte de América) - no disponiendo ni de fuerzas ni de recursos (sobre todo humanos) para poblar y administrar tan extenso territorio, los portugueses dejaron a la colonia una relativa libertad, incluida la religiosa, aunque naturalmente, desde el principio, el factor formal de unificación debía ser (y así fue) el catolicismo lusitano de corte popular, abierto a interferencias sincréticas y ajeno a la ortodoxia teológico-doctrinal. Todo y con la dominación secular y el monopolio formal del catolicismo, existió en Brasil una norma tácita: la aceptación del pluralismo, la tolerancia y la difusión de la religiosidad popular, incluso, de mal o buen grado, de ciertas prácticas africanas e indígenas sincretizando, de forma no oficial, las deidades locales en el panteón ampliado de santos. De ahí, este permanente y generalizado cruzamiento de elementos de diferentes religiones en un único sistema ecléctico (a pesar de que, formalmente, presenta un carácter asimétrico, dado el

p. 240.

44 Malinowski, M. W poszukiwaniu brazylijskości. Gtówne nurty brazylijskiej myśli spotecznej w XX wieku. Warszawa: CESLA, 2011, p. 11-12. 
dominio de los católicos-colonizadores y dado que el catolicismo fue religión oficial en los territorios colonizados). ${ }^{45}$ Pero fueron sobre todo los esclavos africanos y sus descendientes (en apariencia y forma, católicos; en la práctica, prosélitos de cultos sincréticos africanos) quienes ejercieron, desde el principio, una gran influencia en la formación del complicado panorama religioso del Brasil, cuya herencia constituye un rasgo esencial de su religiosidad actual. Esta hetereodoxia, que estribaba en la falta de una conciencia clara en cuanto a las posibles contradicciones de pertenecer simultáneamente a diversos cultos, resultó en gran medida de la tolerancia del catolicismo brasileño, que unió los cultos africanos con las creencia indígenas y las introdujo en sus entrañas, animando, o mejor dicho, más bien obligando, al principio, a sus seguidores a una participación activa en las ceremonias y celebraciones religiosas - muchos de los que se declaran católicos se caracterizan por entregarse a prácticas muy alejadas de la ortodoxia vaticana y un gran número de ellos, en busca de la protección más eficaz, no dudan en dirigir sus pasos hacia otras creencias. Como se indica, pues, los brasileños pueden ser simultáneamente católicos y seguidores de otros cultos, aunando así todo, sincretizando a su gusto y demostrando con ello que en el mundo de la religión no hay nada imposible: "en Navidad van a la Misa del Gallo, en Año Nuevo van a la playa, vestidos de blanco, para rendir honores a su orixá con la esperanza de recibir buenos fluidos. Acaso es posible que todos engañemos? Claro que no. Somos de verdad profundamente religiosos."

Sin embargo, desde el principio de la colonización, lo excepcional en la esfera religiosa del Brasil radicó en el mantenimiento de ese 'tronco único' cristiano y eso a pesar de los contrastes regionales, culturales y sociales. La auténtica multiplicidad de opciones religiosas existentes no impidió, incluso en el caso de la evangelización, la búsqueda de aspectos comunes, de coincidencias y parecidos entre ellas, facilitando así la incorporación al núcleo cultural del catolicismo popular lusitano de elementos de otras religiones. Los colonizadores portugueses 'consumieron' influencias culturales extrañas y las 'digirieron' para crear algo completamente diferente, pero ya del todo brasileńo ${ }^{46}$. Ante todo, este catolicismo sincrético, no ortodoxo, plástico, variado, pudo constituir uno de los factores más importantes en la formación de la unidad brasileña dentro de la diversidad. Justamente, durante el periodo colonial y de lenta construcción de la sociedad brasileña, fue un importante elemento unificador y garante del nacimiento de un núcleo básico, aunque solo a través de la coexistencia pacífica y no formal con otras formas religiosas, entre las cuales se hallaban algunas antagónicas con

45 Como explica Walendziak, T. „Synkretyzm religijny” en: Gawrycki, M.F. (ed.). Dzieje kultury latynoamerykańskiej. Warszawa: Wyd. Naukowe PWN, 2009, pp. 246-256.

46 Eakin, M.C. Historia Ameryki Eacińskiej. Zderzenie kultur. Kraków: WUJ, 2009, p. 257. 
respecto a él ${ }^{47}$. Precisamente de esta interpretación del periodo colonial, procede, por ejemplo, el concepto del 'lusotropicalismo' patriarcal, que explica la extraordinaria facilidad de adaptación cultural de los portugueses a las condiciones de la colonización del Brasil y de rápida elaboración de proyectos eficaces para hacer frente a situaciones dificíles, formándose así de un modo dinámico esa diversidad étnico-cultural de la colonia ${ }^{48}$.

A pesar de la existencia del derecho al patronato, las autoridades laicas del Brasil nunca estuvieron dispuestas a destinar los diezmos recogidos por el tesoro real a fines religiosos y a comprometerse en la misión de hacer del catolicismo formal el monopolio de la fe. A ello se debe que a la Iglesia siempre la faltaran infraestructuras diocesales, que el clero siempre sufriera irregularidad en el pago de sus pensiones de parte de las arcas del rey y, lo que es más importante, a ello se debe también la permanente actividad y presencia en la Iglesia de los laicos (iniciado el hecho por las irmandades), sin lo cual es difícil imaginar la permanencia, desde la base, de influencias del catolicismo y su fuerte sincretización. En esta tradición laica de autogestión y autonomía (aunque a veces muy moderada, e incluso un poco aparente) tiene su origen la decidida resistencia social frente a la elite histórica de la Iglesia y la mucha influencia ejercida por el laicado contemporáneo sobre sus actividades. ${ }^{49}$

Desde el alba de la colonización del Brasil, la Iglesia aseguró a la sociedad en formación unos modelos culturales estables, que posibilitaban la unión con otros pueblos y naciones en una comunidad brasileña única con raíces cristianas, aunque altamente sincréticas. Es más, en la primera fase de la colonización, la cultura misma se desarrolló en gran medida a tenor de las necesidades de la religión y, en estrecha relación con ella, cuando la Iglesia abría y gestionaba sus primeras instituciones en la colonia portuguesa (por ejemplo escuelas). Por consiguiente, el catolicismo tuvo, con toda seguridad, una inmensa influencia sobre todos los elementos culturales de la sociedad brasileña. A decir verdad, , "la conquista espiritual no condujo a la conversión al catolicismo de estilo europeo a los habitantes de todas las regiones, pero sin duda, en mayor o menor medida, saturó su vida de valores ceremonias y creencias católicas" y pese a que las formas de catolicismo practicadas por diferentos segmentos sociales a veces "se diferenciaban extremadamente entre

47 Wagley, Ch. An Introduction to Brazil. New York, London: Columbia University Press, 1963 , p. 233.

48 Acuñado por Freyre, G. Panowie i niewolnicy. Warszawa: PIW, 1985. La imposibilidad de rebatirla ante el hecho de que los portugueses, en vez de liquidarlas, se aprovecharon profusamente de culturas ajenas e importadas, y que el catolicismo traído al Brasil por las misiones evangelizadoras toleró e incluso absorbió elementos extrańos a la propia fe y religión.

49 Acerca de esta permenente, pero constructiva tensión entre el clero y los fieles que luchan en el Brasil en defensa de su autonomía, escribe, entre otros, Brandão, C. Os deuses do povo. São Paulo: Brasiliense, 1980. 
sí, la Iglesia católica las abarcaba todas y se convirtió en parte de la comunidad creada por estos grupos". 50

Así pues, aunque el amplio panorama religioso del Brasil se fue haciendo, en el transcurso de los siglos sucesivos de colonización, cada vez más "armónicamente diversificado", esta armonía estribaba no tanto en la tendencia a la uniformidad, sino más bien en el mantenimiento de un equilibrio religioso singular y pulsante, que conservó el núcleo cultural, básico y fuerte, del cristanismo. Por eso, a pesar de que el actual Brasil es, sin duda y formalmente, un país católico, sigue permaneciendo de todo inmerso en sincretismos sorprendentes y sigue siendo definido por el Vaticano, como lo fue en siglos anteriores, como 'tierra de misión', llena de 'herejías locales', de fantasías religiosas y de antagonismos culturales que conviven entre sí de modo asombroso. Por eso, "no es fácil mostrar una imagen coherente de la cultura brasileña. Nuestros dioses tienen tres rostros diferentes y se comunican al menos en tres lenguas diferentes. Sin embargo, la mayoria de los brasileños posee una sorprendente capacidad de saltar de un código religioso a otro, consiguiendo mantener en todos la misma desenvoltura (...). Un signo de este 'sindrome brasileño' es la alta movilidad religiosa de los fieles, su capacidad para manejar simultáneamente la diversidad de creencias que tenga a mano, la creación de combinaciones inauditas y simplemente una fantasía religiosa increíble (...) Sin embargo, la gente no mezcla estos códigos, no los confunde. Pueden reconocer las diferencias, jugar con ellas y comportarse en diversos contextos religiosos comme il faut. A decir verdad, estos lenguajes religiosos son diferentes y variados, pero no nos encontramos en una torre de Babel'. ${ }^{1}$

La religiosidad de los brasileños constituye un conjunto interminable de combinaciones posibles, aunque a menudo paradójicas, en las que resulta mas fácil buscar una simbiosis doctrinal y un eclecticismo progresivo que una 'guerra de dioses'. Sin embargo, es necesario recordar que el mismo catolicismo brasileño, que a lo largo de los siglos fue perfilando esa religiosidad, no era tampoco una religión coherente y que, bajo la influencia de otras muchas doctrinas, esa diversidad interna se vio intensificada de modo incesante. De ahí, que cuestiones tales como: qué significa ser católico en el Brasil actual, qué significa ser una persona religiosa en ese país o cómo es de verdad la Iglesia allí, siguen siendo difíciles de responder. Pero también cabría recordar que cualquier respuesta a cuestiones relacionadas con la religión, en el contexto brasileño, nunca fue, ni simple, ni unívoca. Por otro lado, la sola existencia de la religión es un valioso recordatorio de que existen límites que las explicaciones científicas no pueden traspasar. Por lo tanto, a la ciencia le está permitido establecer los límites de su competencia, pero ello no significa que lo que se encuentra fuera de ellos, no es importante (o que no existe).

50 Como explica Eakin, M.C. Historia Ameryki Eacińskiej. Zderzenie kultur. Kraków: WUJ, 2009, p. 207.

51 Fernandes, R.C. Romarias da Paixão. Rio de Janeiro: Rocco, 1994, p. 121. 